\title{
Analisis Kelayakan Investasi Sistem Informasi Pendistribusian Produk Menggunakan Metode Cost Benefit Analysis Pada PT.Guna Atmaja Jaya
}

\author{
(ITS) \\ E-mail:djraka21@gmail.com
}

Raka Aryo Kinanthi, Sholiq, dan Hanim Maria Astuti

Departemen Sistem Informasi, Fakultas Teknologi Informasi, Institut Teknologi Sepuluh Nopember

\begin{abstract}
Abstrak-Investasi terhadap suatu sistem informasi yang berupa aplikasi terus dilakukan karena banyak pengaruh yang akan dihasilkan ketika suatu teknologi informasi ditanamkan pada suatu perusahaan seperti adanya hubungan antar biaya teknologi informasi dengan performa ekonomi dari perusahaan. Dalam kasus ini PT. Guna Atmaja Jaya ingin mencari kelayakan investasi teknologi informasi yang akan di terapkan pada perusahaan. PT.Guna Atmaja Jaya ingin adanya teknologi informasi yang modern yang dapat meningkatkan profit perusahaan dengan mencoba memangkas cara manual perusahaan dalam melakukan pendistribusian produk. Dengan begitu sebelum beranjak terlalu jauh akan dilakukan analisa kelayakan investasi teknologi agar dapat mendapatkan teknologi informasi yang sesuai dengan kebutuhan perushaan. Salah satu cara untuk memproses manajemen biaya dan menentukan keuntungan dari setiap alternatif yaitu dengan Cost Benefit Analyst (CBA), menggunakan metode Cost Benefit akan terdapat beberapa rumus yang digunakan sebagai acuan dalam penghitungan nilai dan manfaat seperti PP (Payback period),NPV (Net Present Value), ROI (Return Of Investmen), IRR (Internal Rate Return). Dengan didapati nilai dari pengihitungan menggunakan rumus tersebut maka nilai - nilai tersebut akan dilakukan perbandingan harga yang berfungsi untuk mendapatkan nilai yang paling layak dan sesuai dengan keinginan perusahaan. Dengan melakukan penelitian ini PT.Guna Atmaja Jaya akan mendapatkan rekomendasi investasi mana yang layak dan sesuai dengan kebutuhan dari perusahaan. Menimbang juga PT.Guna Atmaja Jaya akan menyesuaikan dengan biaya yang telah di rencanakan sejak awal.
\end{abstract}

Kata kunci-Kelayakan investasi , pendistribusian ,cost benefit analyst.

\section{PENDAHULUAN}

$\mathrm{P}$ GUNA ATMAJA JAYA merupakan salah satu perusahaan yang akan menanamkan teknologi informasi pencatatan persediaan produk. PT.Guna Atmaja Jaya adalah sebuah perusahaan yang bergerak di bidang industri cigars, cigarettes, tobbaco ( retail) dan cigars, cigarettes, tobbaco ( manufacture, wholesale) di Kabupaten Tulungagung, Jawa timur. Produk yang di produksi oleh PT. Guna Atmaja Jaya berupa 2 jenis rokok yaitu rokok mild dan rokok kretek dengan berbagai macam merk seperti mix max mild, mix max mild red, arif special, arif special menthol, jong spirit. Sejak berdiri pada tahun 2006 PT.Guna Atmaja Jaya menerapkan sistem manual untuk penjualan produk ke agen - agen di daerah jawa, sulawesi , kalimantan dengan menggunakan salesman sebagai kurir yang mencatat seluruh keluar masuk produk dari pabrik ke agen. Dengan begitu perusahaan akan banyak membutuhkan tenaga kerja ( salesman ) untuk mendapatkan data dari tiap agen untuk di masukan kedalam database perusahaan yang di gunakan sebagai data produktivitas perusahaan.

PT.Guna Atmaja Jaya memiliki rangkaian metode penjualan produk yang mempunyai tujuan untuk menyampaikan produk kepada konsumen. Disini PT.Guna Atmaja Jaya ingin mengurangi biaya pengeluaran yang di gunakan untuk pemasaran produk dengan cara menerapkan sistem baru yang dapat mempersingkat rangkaian metode pemasaran sehingga perusahaan dapat menekan biaya pengeluaran untuk pegawai khususnya salesman dan dapat meningkatkan profit bagi perusahaan. Dari permasalahan ini lah akan digunakan metode CBA ( cost benefit analyst) yang dapat memberikan rekomendasi untuk perusahaan tentang keleyakan investasi yang akan dilakukan mengingat biaya yang di keluarkan oleh perusahaan terbatas. Untuk menunjukkan kelayakan suatu investasi terdapat beberapa rumusan yang dapat digunakan. Rumusan tersebut antara lain, Net Present Value (NPV), Payback Period, Benefit/Cost Ratio (B/C Ratio), Internal Rate of Return (IRR) dan Modified Internal Rate of Return (MIRR).

Cost Benefit Analyst (CBA) adalah metode yang melakukan pendekatan secara sistematis untuk mendapatkan rekomendasi kebijakan yang memungkinkan analisis membandingkan dan menganjurkan suatu kebijakan dengan menghitung total biaya dalam bentuk uang dan total keuntungan dalam bentuk uang. Cost Benefit Analyst dapat digunakan sebagai alat pengambilan keputusan pada saat akan melakukan investasi teknologi informasi. Metode ini menggabungkan berbagai macam perhitungan sehingga para pengambil keputusan dapat lebih baik dalam memilih alternatif mana yang memberikan pengembalian yang maksimum dengan biaya yang minimum sesuai dengan perhitungan yang telah dilakukan dengan menggunakan CBA. Dalam penelitian Analisis Kelayakan Investasi Teknologi Informasi Menggunakan Metode CostBenefit yang ditulis oleh [1] Jiesianti, Kaunang, Stanley, Yaulie dan Rindengan, telah memanfaatkan metode Cost Benefit Analyst dalam perhitungan investasi. Dalam penelitian ini 
dijelaskan bagaimana cara menghitung suatu kelayakan dari investasi IT yang telah digunakan dalam suatu perusahaan dengan melihat apakah manfaat dari suatu investasi di perusahaan dapat meningkatkan kualitas material maupun nonmaterial [1]. Perbandingan alternative juga akan dilakukan didalam penelitian ini yang bertujuan untuk mendapatkan hasil yang terbaik dan layak untuk perusahaan dalam melakukan investasi sistem informasi.

Oleh karena itu untuk menentukan investasi ini layak atau tidak di tanamkan pada PT.Guna Atmaja Jaya digunakan metode cost benefit analyst yang melalui beberapa rangkaian identifikasi dan proses yang akan menghasilkan suatu rekomendasi yang terbaik bagi PT.Guna Atmaja Jaya..

\section{DASAR TEORI}

\section{A. Investasi Teknologi Informasi}

Investasi Teknologi Informasi terdiri dari total biaya siklus hidup keseluruhan proyek atau potongan proyek yang melibatkan proyek Teknologi Informasi, termasuk biaya operasional pasca proyek sistem yang diterapkan. Investasi Teknologi Informasi akan muncul lagi ketika Teknik Informasi akan diganti atau dihilangkan dengan alasan apapun. Menurut uraian diatas dapat disimpulkan bahwa Investasi Teknologi Informasi adalah perencanaan pengeluaran uang untuk pengadaan Teknologi Informasi yang berfungsi untuk mendukung kinerja perusahaana dalam mencapai rencana strategis perusahaan.

\section{B. Analisa Kelayakan}

Salah satu tantangan terbesar dalam menilai kelayakan sebuah investasi pembangunan teknologi informasi adalah menilai atau memperkirakan manfaat apa yang diperoleh oleh perusahaan nantinya [2]. Dikatakan sebagai tantangan karena kebanyakan manfaat yang diberikan oleh teknologi informasi bersifat intangible atau sulit dikuantifikasikan ke dalam satuan angka finansial dan tidak secara langsung berpengaruh terhadap profitabilitas perusahaan. Studi kelayakan bisnis akan menyangkut tiga aspek yaitu, aspek manfaat ekonomis bagi usaha itu sendiri, aspek manfaat ekonomis usaha tersebut bagi negara tempat usaha tersebut dilaksanakan, dan aspek manfaat sosial usaha tersebut [3] Cost Benefit Analysis

\section{METODOLOGI PENELITIAN}

Bab ini menjelaskan metode penelitian yang digunakan dalam pengerjaan studi. Metode penelitian ini diperlukan sebagai panduan agar pada setiap tahapan pengerjaan dapat berjalan terarah dan sistematis. Berikut tahapan pengerjaan studi:

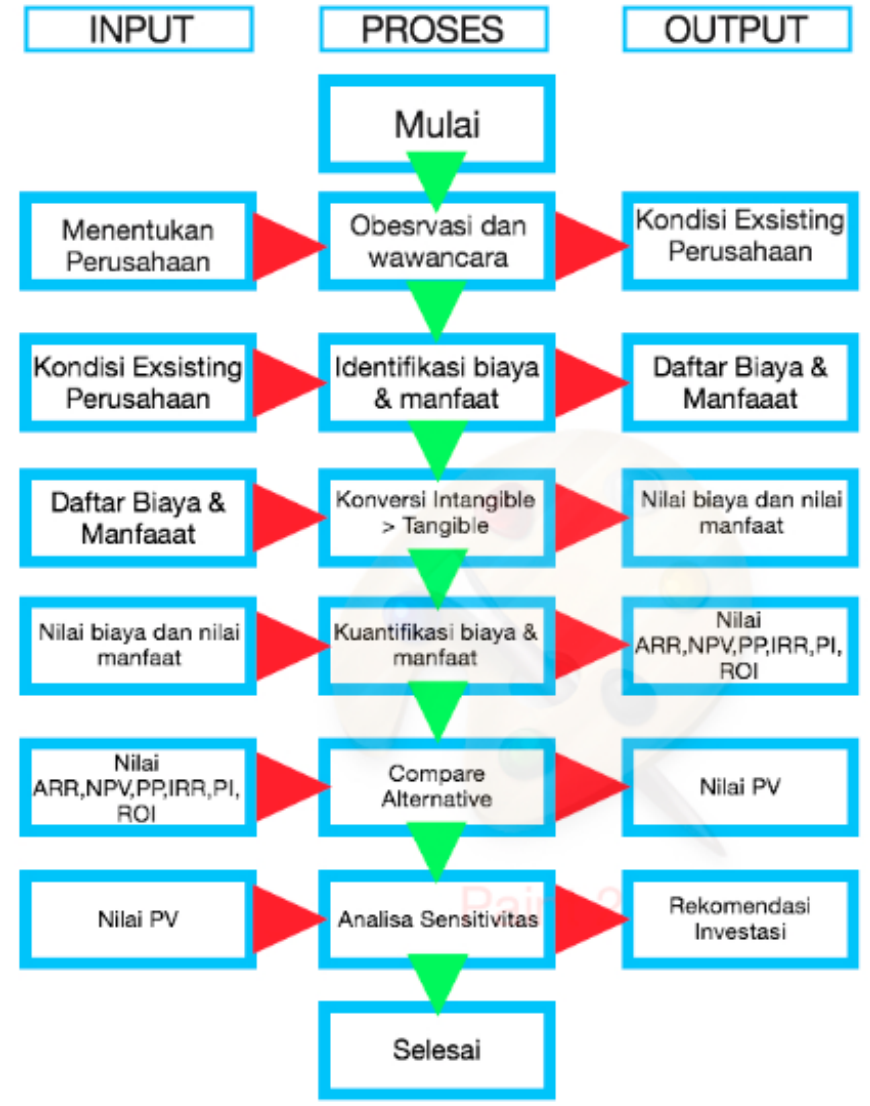

Gambar 1. Metodologi Penelitian

\section{HASIL DAN PEMBAHASAN}

Dalam uraian penelitian ini akan dijelaskan lebih detail mengenai :

\section{A. Hasil Compare Alternative}

Hasil analisis dengan menggunakan Compare Alternative yaitu dengan melakukan perbandingan antara ketiga vendor yang memiliki nilai keuntungan tertinggi yaitu dengan melakukan perbandingan pencapain benefit dari masingmasing vendor dengan mempertimbangan tingkat pengembalian atas investasi yang dilakukan. Berdasarkan hasil perbandingan tingkat pengembalian investasi yang akan dilakukan menunjukkan bahwa investasi untuk vendor $\mathrm{C}$ memiliki petensi pemgembalian tertinggi yaitu mencapai sebesar $2,83 \%$, A sebesar $0,74 \%$ dsan untuk vendor B yaitu sebesar $0,314 \%$. Perbandingan ini menunjukkan bahwa vendor $\mathrm{C}$ memiliki tingkat pengembalian investasi tertinggi.

\section{B. Analisa Sensitivitas}

Dari hasil penghitungan menggunakan metode Cost Benefit Analysis didapati nilai NPV, Payback Period, IRR, ARR, PI dan ROI dan terjadi perbedaan nilai pada kondisi perusahaan dalam keadaan normal. Sehingga dapat disimpulkan bahwa pada saat pencapaian minimum target produksi maka akan terjadi perubahan keuntungan yang sangat signifikan maka proyek ini dapat dikatakan sensitif terhadap peningkatan resiko tercapainya target minimum produksi, dengan membandingkan 
nilai normal dengan nilai setelah melakukan investasi IT pada bagian pendistribusian produk pada PT.Guna Atmaja Jaya.

Tabel 1.

Analisa Sensitivitas

\begin{tabular}{cccc}
\hline \hline vendor & A & B & C \\
\hline NPV & 78.999 .430 & 46.465 .594 & 426.459 .483 \\
PP & 0,14 & 0,43 & 0,637 \\
IRR & $8,15 \%$ & $1,100 \%$ & $21,94 \%$ \\
ARR & $43,42 \%$ & $12,24 \%$ & $104,96 \%$ \\
PI & 1,69 & 1,331 & 2,47 \\
ROI & $0,74 \%$ & $0,314 \%$ & $2,83 \%$ \\
\hline \hline
\end{tabular}

C. Hasil Rekomendasi

Pada tahap ini akan dilakukan pembahasan mengenai hasil rekomendasi investasi IT yang layak untuk diterapkan pada PT.Guna Atmaja Jaya. Berikut adalah hasil rekomendasi dari hasil pengihitungan uji kelayakan investasi IT menggunakan metode Cost Benefit Analysis.

\section{Tabel 2.}

Hasil Pengihitungan Uji Kelayakan Investasi IT Menggunakan Metode Cost

\begin{tabular}{ccc}
\multicolumn{3}{c}{ Benefit Analysis } \\
\hline \hline COST & & JUMLAH \\
\hline VENDOR A & IDR & $20.648 .808,00$ \\
VENDOR B & IDR & $183.997 .391,00$ \\
VENDOR C & IDR & $237.289 .014,00$ \\
BENEFIT & & JUMLAH \\
VENDOR A & IDR & $254.811 .200,00$ \\
VENDOR B & IDR & $282.304 .929,00$ \\
VENDOR C & IDR & $732.049 .438,00$ \\
BENEFIT - COST & & JUMLAH \\
VENDOR A & IDR & $234.162 .392,00$ \\
VENDOR B & IDR & $98.307 .538,00$ \\
VENDOR C & IDR & $494.760 .424,00$ \\
\hline \hline
\end{tabular}

Hasil penghitungan Cost Benefit Analysis terhadap beberapa vendor yang ingin melakukan kerja sama dengan PT.Guna Atmaja Jaya dalam melakukan investasi IT menunjukkan bahwa vendor $\mathrm{C}$ memiliki potensi yang besar untuk memberikan jaminan keuntungan yang akan diperoleh perusahaan. Jaminan keuntungan sebesar ini menjadikan aktivitas yang dilakukan dengan mengunakan vendor $\mathrm{C}$ ini ditunjukkan dengan nilai tertinggi yang diperoleh dari vendor $\mathrm{C}$ dari hasil investasi yang dilakukan.

\section{KESIMPULAN PENELITIAN}

Kesimpulan yang dapat diambil dari pengerjaan Studi ini yakni sebagai berikut:

1. Hasil analisis menunjukkan bahwa cost yang di hasilkan sesuai dengan cost yang telah di sediakan oleh perusahaan, yang ditunjukkan dengan nilai investasi yang dikeluarkan oleh perusahaan dengan proyeksi tingkat keuntungan yang dihasilkan.

2. Alternatif yang akan muncul pada penelitian ini yaitu dalam melakukan investasi terdapat 3 pilihan aktivitas investasi yang dilakukan yaitu dengan menggunakan tiga vendor yang berbeda.

3. Investasi ini layak berdasarkan analisis yang sudah dilakukan menggunakan Cost Benefit Analysis menunjukkan bahwa penggunaan vendor $\mathrm{C}$ memiliki hasil yang paling layak untuk dilakukan investasi, dimana vendor tersebut menawarkan keuntungan yang tertinggi dengan nilai tingkat pengeembalian investasi terbesar.

4. Tingkat penghematan setelah melakukan investasi dalam pendistribusian ini ditunjukkan dengan analisis kelayakan dalam melakukan investasi yang dilakukan, dimana dalam aktivitas investasi perusahaan dapat mengetahui tingkat pengembalian investasi dan hasil yang diperoleh dari aktivitas investasi yang dilakukan.

\section{DAFTAR PUSTAKA}

Y. Doerachman, J. D., Kaunang, I. S., Stanley, “Analisa Kelayakan Investasi TI menggunakan Metode Cost Benefit," 2012.

[2] R. E. Indrajit, "Kajian Strategis Analisa Cost-Benefit Inverstasi Teknologi Informasi," 2010.

[3] M. Hansen, D. R., \& Mowen, Management Accounting, 7th edition. South Western Cengage Learning, 2005. 